\title{
OPTIMASI KOMPOSISI TEPUNG BERAS DAN FRAKSI ETANOL DAUN SENDOK (Plantago major, L) \\ DALAM FORMULASI TABIR SURYA DENGAN METODE SIMPLEX LATTICE DESIGN
}

\section{OPTIMIZATION COMPOSITION OF RICE FLOUR AND ETHANOL FRACTION OF Plantago major, L LEAF IN FORMULATION OF SUNSCREEN BY SIMPLEX LATTICE DESIGN METHOD}

\author{
Nining Sugihartini \\ Fakultas Farmasi Universitas Ahmad Dahlan Yogyakarta \\ Email:irmaningsih75@yahoo.com
}

\begin{abstract}
Abstrak
Oktil metoksisinamat (OMS) merupakan bahan aktif tabir surya yang akan mengalami degradasi setelah mendapat paparan sinar matahari. Di lain pihak, antioksidan memiliki potensi sebagai fotoprotektor sehingga dalam penelitian ini digunakan fraksi etanol daun Plantago major, L untuk mendukung potensi OMS. Selain itu ditambahkan juga tepung beras karena memiliki kemampuan untuk memantulkan cahaya matahari. Penelitian ini bertujuan untuk mendapatkan komposisi optimum keduanya berdasarkan efektifitas OMS. Pada penelitian ini digunakan tiga formula berdasarkan metode simplex lattice design dengan perbandingan fraksi etanol daun Plantago major, L dan tepung beras sbb: FI (100\%:0\%), formula II (50\%:50\%), formula III (0\%:100\%). Ketiga formula dipaparkan cahaya matahari selama 5 jam (pukul 09.00-14.00 WIB) dengan setiap interval satu jam sampel diambil untuk ditetapkan nilai \% transmisi eritema (\%Te) dan pigmentasi (\%Tp). Data yang diperoleh kemudian dianalisis untuk ditetapkan komposisi optimum yaitu yang memberikan nilai respon tertinggi. Hasil penelitian menunjukkan bahwa penambahan 100\% tepung beras merupakan penambahan yang paling optimum untuk mendukung aktivitas OMS sebagai tabir surya dengan penurunan \% transmsisi eritema sebesar $200 \%$ dan pigmentasi sebesar $75 \%$.
\end{abstract}

Kata kunci : Oktil metoksisinamat, tepung beras, fraksi etanol daun Plantago major, L, nilai \% transmisi eritema, nilai \% transmisi pigmentasi. 


\begin{abstract}
Octyl methoxycinnamate is an active ingredient in sunscreen that will be degradated after exposure by sunlight. On the other hand, antioxidants have potential capability as photoprotector which in this study is used the ethanol fraction of leaf of Plantago major, L to support activity of OMS. In addition, rice flour is added too because it has the ability to reflect sunlight. The aim of this study is to obtain the optimum composition of them, based on the effectivity of OMS. This study used three formulas based on the simplex lattice design method with a comparison of octyl methoxycinnamate and rice flour as follows: FI (100\%: 0\%), the formula II (50\%: $50 \%)$, formula III (0\%: 100\%). All formulas were exposured by sunlight for 5 hours (at 09:00 to 14:00 GMT) and in interval one hour samples were taken to measure the value of \% erythema transmission (\% Te) and pigmentation (\% Tp). Data were analysed to get the optimum composition which has the highest of response. The results showed that $100 \%$ rice flour was the optimum addition to support activity of OMS as sunscreen with decreasing of \% erythema transmission and pigmentation was 200\%, 75\%, respectively.
\end{abstract}

Keywords : Octyl methoxycinamate, rice flour, fraction of leaf ethanol extract Plantago major, L, Sunscreen. 


\section{PENDAHULUAN}

Cahaya matahari sangat dibutuhkan oleh semua makhluk hidup untuk kelangsungan hidupnya. Di sisi lain intensitas cahaya matahari yang tinggi dapat mengakibatkan kerusakan pada sebagian tubuh manusia. Apabila kulit terpapar cahaya matahari dalam intensitas yang tinggi dan dalam jangka waktu yang lama, dapat menyebabkan terjadinya kerusakan kulit. Oleh karena itu perlu upaya untuk melindungi kulit dari sengatan cahaya matahari.

Salah satu produk yang banyak digunakan untuk melindungi kulit adalah sediaan tabir surya. Mekanisme kerja tabir surya ada dua macam, yaitu menyerap cahaya matahari dan memantulkan kembali cahaya matahari yang mengenai kulit.

Banyak zat aktif yang dipergunakan dalam sediaan tabir surya, salah satu diantaranya adalah oktil metoksisinamat (OMS). Mekanisme kerja bahan ini secara kimiawi adalah dengan mengabsorbsi sinar ultra violet (UV) sehingga menghambat penetrasi sinar UV ke dalam lapisan epidermis kulit. Namun hasil penelitian menunjukkan bahwa OMS dapat mengalami degradasi setelah digunakan (Astuti, 1997). Oleh karena itu perlu pengembangan formula dengan penambahan bahan lain yang akan mendukung aktivitas OMS.

Bahan aktif lain yang dapat digunakan adalah flavonoid dalam daun sendok (Plantago major, L) yang berkhasiat sebagai antioksidan. Antioksidan dapat berfungsi sebagai fotoprotektor (Black, 1990). Di sisi lain tepung beras yang mengandung amilum dapat memantulkan sinar matahari secara fisik.

Berdasarkan potensi dari kedua bahan tersebut maka perlu dikembangkan formula tabir surya dengan bahan aktif OMS dengan menambahkan kedua bahan tersebut untuk mendukung aktivitas OMS sehingga perlindungan bagi kulit akan lebih meningkat.

Metode yang digunakan dalam mendapatkan komposisi optimum adalah dengan simplex lattice design yaitu suatu cara atau teknik untuk memprediksi profil respon yang dipengaruhi oleh komposisi campuran bahan sebagai faktornya. Profil tersebut dapat digunakan untuk memprediksi perbandingan komposisi campuran bahan yang memberikan respon optimum seperti yang diharapkan.

\section{Jalannya Penelitian}

\section{Bahan dan Alat}

Bahan yang digunakan dalam penelitian ini adalah : Oktil metoksisinamat (PT. Vitapharm, Surabaya), silika gel G, aquades dan aquabides (kualitas farmasi). Metanol dan etanol (p.a E.Merck), kertas saring Whatman 40. Daun Plantago major, L (dari kaliurang), Tepung beras dari pasar bringharjo.

Sedangkan alat yang dipergunakan dalam penelitian ini adalah : Spektrofotometer UV-1601PC (Shimadzu, Japan), neraca analitik AR2140 Ohaus (New York), penyaring Whatman, alat pembuat lapis tipis, Lempeng kaca ukuran $5 \times 20 \mathrm{~cm}$, Pipet mikro, Sudip, Alat-alat gelas. 


\section{METODE PENELITIAN}

\section{Menyiapkan fraksi etanol daun Plantago major, $\mathrm{L}$}

Serbuk daun Plantago major, L kering diinfundasi selama 15 menit pada suhu $90^{\circ} \mathrm{C}$ kemudian disertai panas. Filtrat diuapkan di atas penangas air sampai kental kemudian ditambahkan etanol berkali-kali sehingga larutan etanol terakhir tidak berwarna lagi kemudian disentrifugasi dengan kecepatan $2500 \mathrm{rpm}$. Filtrat dievaporasi sampai hampir kering (selanjutnya disebut fraksi etanol).

\section{Pembuatan formula sediaan}

Pada pembuatan sampel maka berat bahan aktif yang digunakan adalah satu gram. Adapun komposisi masingmasing bahan pada tiap formula disusun berdasarkan metode Simplex Lattice Design seperti yang disajikan pada tabel I.

Tabel I. Komposisi tepung beras dan fraksi daun Plantago major, L berdasarkan metode Simplex Lattice Design

\begin{tabular}{|c|c|c|}
\hline Formula & Tepung Beras & $\begin{array}{c}\text { Fraksi etanol daun } \\
\text { Plantago major, } \mathbf{L}\end{array}$ \\
\hline I & 100 & 0 \\
\hline II & 50 & 50 \\
\hline III & 0 & 100 \\
\hline
\end{tabular}

Pembuatan sampel untuk masingmasing formula adalah sebagai berikut:

Tepung beras dan oktil metoksisinamat masing-masing ditimbang sesuai komposisi dalam formula dengan berat total sebanyak 1 gram. Dimasuk- kan kedalam erlenmeyer bertutup yang sudah ditara, kemudian 15 gram silika gel $\mathrm{G}$ dimasukkan, dan ditambah air suling $30 \mathrm{ml}$ kemudian ditimbang. Lapisan lempeng kaca ukuran $5 \times 20 \mathrm{~cm}$ yang diketahui beratnya disiapkan 10 lempeng, dan diletakkan diatas pembuat lapis tipis. Formula segera dikocok kuat dan cepat, kemudian diratakan diatas lempeng kaca dengan ketebalan 0,25 $\mathrm{mm}$. dalam keadaan basah masingmasing lempeng ditimbang dan disimpan ditempat yang terlindung dari cahaya.

\section{Penyinaran sampel}

Masing-masing formula (18 sampel) diletakkan pada rak atau tempat yang sesuai, diberi perlakuan dengan disinari langsung di tempat terbuka pada sinar matahari, dengan interval waktu satu jam, dimulai dari pukul 09.00-14.00 WIB. Untuk pembanding masingmasing formula (6 lempeng) diperlakukan tanpa penyinaran $(0$ jam $)$. Setiap 


\section{Penentuan efektivitas oktil metok- sisinamat}

Sampel yang sudah mengalami penyinaran (5 jam) dan belum diukur serapannya dengan spektrofotometer pada panjang gelombang 292,5 - 372,5 nm. Dari nilai serapan yang diperoleh dihitung nilai serapan untuk $1 \mathrm{~g} / 1$ dan $\mathrm{T}$ (\%) $1 \mathrm{~g} / \mathrm{l}$ dengan rumus $\mathrm{A}=-\log \mathrm{T}$. Nilai transmisi eritema dihitung dengan cara mengalikan nilai transmisi $(\mathrm{T})$ dengan faktor efektivitas eritema (Fe) pada panjang gelombang 292,5-372,5 $\mathrm{nm}$. Nilai transmisi pigmentasi dihitung dengan cara mengalikan nilai transmisi (T) dengan faktor efektivitas pigmentasi
Nilai persen transmisi eritema dan pigmentasi oktil metoksisinamat yang mendapat perlakuan paparan cahaya matahari selama 0 dan 5 jam dari formula I, formula II dan formula III kemudian dimasukkan dalam persamaan berdasarkan simplex lattice design.

\section{HASIL DAN PEMBAHASAN}

Parameter yang digunakan untuk menentukan komposisi optimum adalah nilai $\%$ transmisi eritema $(\% \mathrm{Te})$ dan nilai $\%$ transmisi pigmentasi (\%Tp). Data nilai \% transmisi eritema dan nilai \% transmisi pigmentasi dapat dilihat pada gambar 1 dan 2.

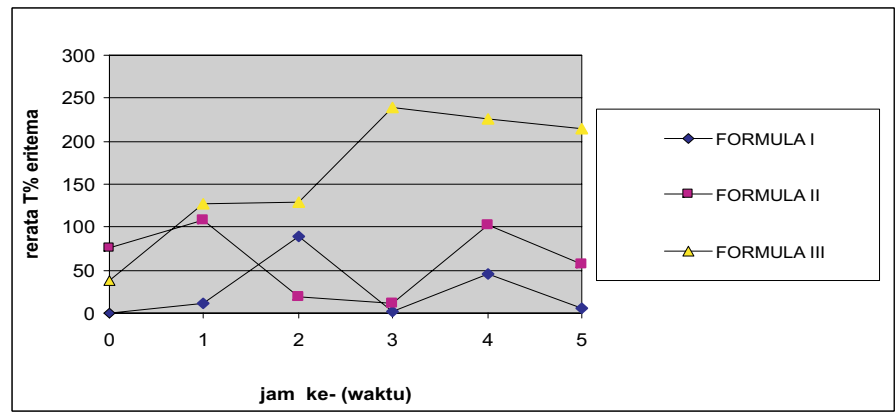

Gambar 1. Grafik \% transmisi eritema OMS pada berbagai campuran fraksi etanol daun Plantago major, $L$ dan tepung beras

(Fp) pada panjang gelombang 292,5$372,5 \mathrm{~nm}$. Selanjutnya nilai persen transmisi eritema dan nilai persen transmisi pigmentasi dihitung berdasarkan persamaan 1 dan 2 (Cumpelik, 1972).

$$
\begin{aligned}
& \% \text { transmisi eritema }=\frac{\sum \mathrm{TxFe}}{\sum \mathrm{Fe}} \\
& \% \text { transmisi pigmentasi }=\frac{\sum \mathrm{TxFp}}{\sum \mathrm{Fp}}
\end{aligned}
$$

\section{Analisa Data}

Persen transmisi eritema menggambarkan jumlah sinar matahari yang diteruskan setelah mengenai tabir surya sehingga dapat menyebabkan eritema kulit (kulit menjadi kemerahan). Demikian juga \% transmisi pigmentasi yang menggambarkan jumlah sinar matahari yang diteruskan setelah mengenai tabir surya sehingga dapat menyebabkan pigmentasi kulit (kulit menjadi lebih gelap). Berdasarkan hal tersebut maka semakin kecil nilai \% 


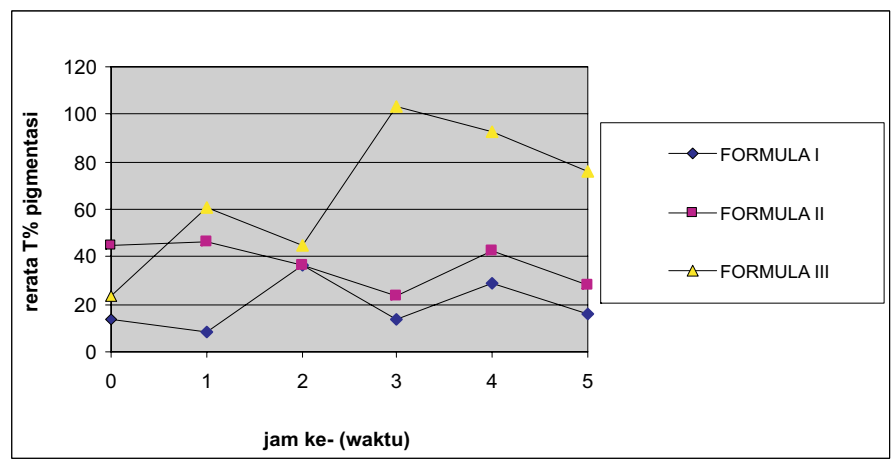

Gambar 2. Grafik \% transmisi pigmentasi OMS pada berbagai campuran fraksi etanol daun Plantago major, $\mathrm{L}$ dan tepung beras

transmisi eritema maupun pigmentasi berarti potensi tabir surya dalam melindungi kulit menjadi lebih baik.

Semakin lama penyinaran maka nilai $\%$ transmisi eritema maupun pigmentasi cenderung semakin besar terutama terlihat pada formula III (gambar 1 dan 2). Hal ini berarti potensi perlindungan terhadap kulit semakin menurun. Ini disebabkan semakin lama penyinaran maka semakin banyak OMS yang ter- degradasi. Akibatnya semakin sedikit sinar matahari yang dapat diserap oleh OMS sehingga semakin banyak sinar matahari yang diteruskan yang akan mengenai kulit.

Penentuan komposisi optimum campuran fraksi etanol daun Plantago major, $\mathrm{L}$ dan tepung beras berdasarkan nilai $\%$ transmisi eritema dan pigmentasi pada jam ke-5. Hal tersebut berdasarkan asumsi bahwa penyinaran yang dilakukan sudah cukup lama sehingga sudah dapat diketahui tingkat perubahan nilai $\%$ transmisi eritema maupun pigmentasinya dibandingkan dengan sebelum penyinaran. Nilai transmisi eritema dan nilai transmisi pigmentasi pada jam ke-5 tersebut kemudian dibuat kurva berdasarkan persamaan Simplex Lattice Design (gambar 3 dan 4).

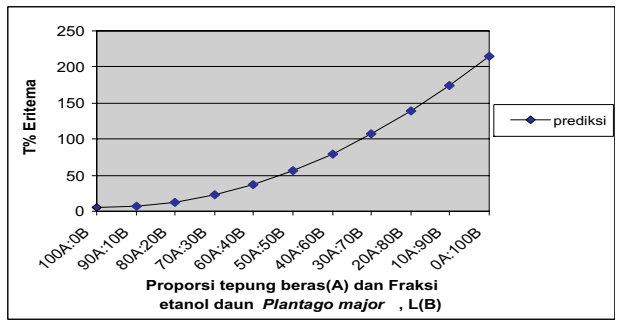

Gambar 3 . Profil nilai \% transmisi eritema berdasarkan simplex lattice design

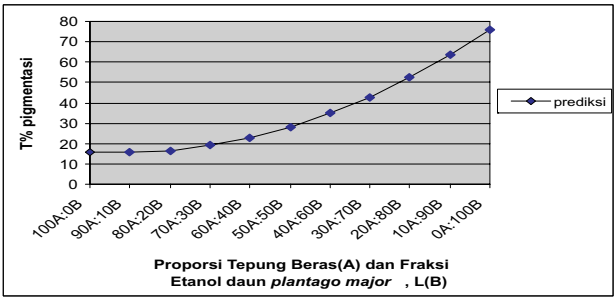

Gambar 4 . Profil nilai \% transmisi pigmentasi berdasarkan simplex lattice design 
Formula $100 \%$ tepung beras (tanpa fraksi etanol daun Plantago major, $\mathrm{L}$ ) menunjukkan nilai $\mathrm{T} \%$ eritema yang paling kecil dibandingkan dengan campuran formula lainnya (gambar 3). Eritema disebabkan oleh sinar UV B sedangkan fraksi etanol daun Plantago major, $\mathrm{L}$ memiliki $\lambda$ maksimal pada daerah sinar UV A sehingga fungsi perlindungan terhadap eritema menjadi kurang maksimal. Di sisi lain tepung beras merupakan suatu bahan yang bisa memantulkan atau menghamburkan cahaya matahari yang salah satu komponen di dalamnya adalah sinar UV $\mathrm{B}$ sehingga tepung beras mampu menurunkan $\%$ transmisi eritema. Penambahan $100 \%$ tepung beras dapat menurunkan nilai \% transmisi eritema sekitar 200\%.

Demikian juga untuk perlindungan terhadap pigmentasi ternyata formula $100 \%$ tepung beras (tanpa fraksi etanol daun Plantago major, L) juga menunjukkan nilai $\mathrm{T} \%$ pigmentasi yang paling kecil dibandingkan dengan campuran formula lainnya (gambar 4). Penambahan $100 \%$ tepung beras dapat menurunkan nilai \% transmisi pigmentasi sekitar $75 \%$.

Hasil ini tentu saja tidak sejalan dengan kenyataan bahwa daya serap maksimal fraksi etanol daun Plantago major, L pada daerah UV A yang diketahui sebagai sinar yang bertanggung jawab terhadap timbulnya pigmentasi. Dengan demikian semakin banyaknya fraksi etanol maka seharusnya fungsi perlindungan terhadap pigmentasi semakin besar yang ditunjukkan dengan nilai $\%$ transmisi pigmentasi yang kecil. Hal ini semakin menunjukkan bahwa aktivitas tepung beras sebagai tabir surya secara fisis yaitu dengan memantulkan atau menyebarkan sinar matahari secara langsung ternyata lebih baik dibandingkan dengan fraksi etanol daun Plantago major, L.

Berdasarkan simplex lattice design maka formula optimum adalah formula yang memiliki nilai respon total paling tinggi. Dalam penelitian ini respon total merupakan gabungan dari dua parameter yaitu \% transmisi eritema dan pigmentasi yang masing-masing diberi pembobotan 50\%. Hal tersebut berdasarkan pemikiran bahwa keduanya memiliki pengaruh yang sama terhadap timbulnya kerusakan pada kulit.

Dalam penelitian ini formula optimum ditunjukkan oleh campuran yang memiliki respon total paling kecil karena respon total yang paling kecil dapat diartikan bahwa kemungkinan terjadinya eritema dan pigmentasi semakin kecil atau kemampuan tabir surya untuk melindungi kulit dari terjadinya eritema dan pigmentasi semakin besar. Hasil perhitungan respon total disajikan pada gambar 5.

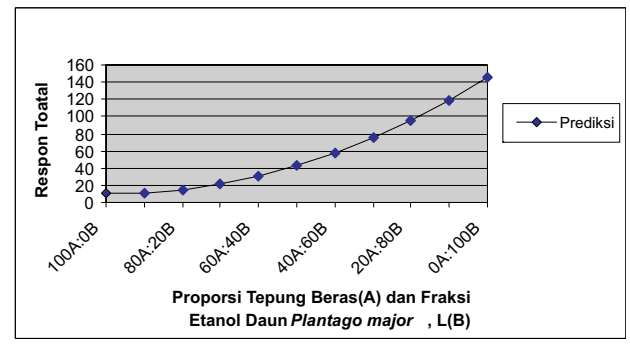

Gambar 5. Profil respon total formula optimum tepung beras dan fraksi etanol daun Plantago major, L sebagai tambahan OMS pada tabir surya 
Hasil perhitungan menunjukkan bahwa respon total yang paling kecil adalah pada penambahan tepung beras sebesar $100 \%$ sehingga proporsi ini merupakan formula optimum dalam penambahan campuran fraksi etanol daun Plantago major, L dan tepung beras.

\section{KESIMPULAN}

Komposisi $100 \%$ tepung beras sebagai komposisi optimum pendukung oktil metoksisinamat sebagai tabir surya.

\section{UCAPAN TERIMA KASIH}

Penelitian ini terlaksana berkat dana Penelitian Reguler dari Lembaga Penelitian dan Pengembangan UAD

\section{DAFTAR PUSTAKA}

Astuti, R., 1997, Fotostabilitas Oktil Metoksisnamat dan Pengaruhnya Terhadap Fotostabilitas Triptofan, Tesis, Program Pasca Sarjana
Universitas Gadjah Mada, Yogyakarta.

Black, H.S., 1990, Antioxidant and Carotenoids as Potential Photoprotectants, in Nicholas, J.L., Nadim, A.S., (Eds.), Sunscreens Development, Evaluation and Regulatory Aspect, Vol. 10, 267-273, Marcel Dekker Inc., New York.

Cumpelik, B.M., 1972, Analytical Procedure and Evaluation of Sunscreen, J. Soc. Cosmetic Chem., 25.3, 333-34

Diffey, B., 2001, Sunscreen isn't Enough, J. Photochem. Photobiol., 64, 105-108.

Hertiani, T., 2000, Isolasi dan Identifikasi Senyawa flavonoid Antioksidan dari Daun Plantago major L., Tesis, Program Pasca Sarjana, Universitas Gadjah Mada, Yogyakarta. 